K. LIAO, Y.-F. YANG, Y. LI, J. N. SANDERS, K. N. HOUK, D. G. MUSAEV, H. M. L. DAVIES* (EMORY UNIVERSITY, ATLANTA AND UNIVERSITY OF CALIFORNIA, LOS ANGELES, USA; ZHEIJANG UNIVERSITY OF TECHNOLOGY, HANGZHOU, P. R. OF CHINA)

Design of Catalysts for Site-Selective and Enantioselective Functionalization of Non-activated Primary C-H Bonds Nat. Chem. 2018, 10, 1048-1055.

\title{
Enantioselective Functionalization of Primary C-H Bonds
}

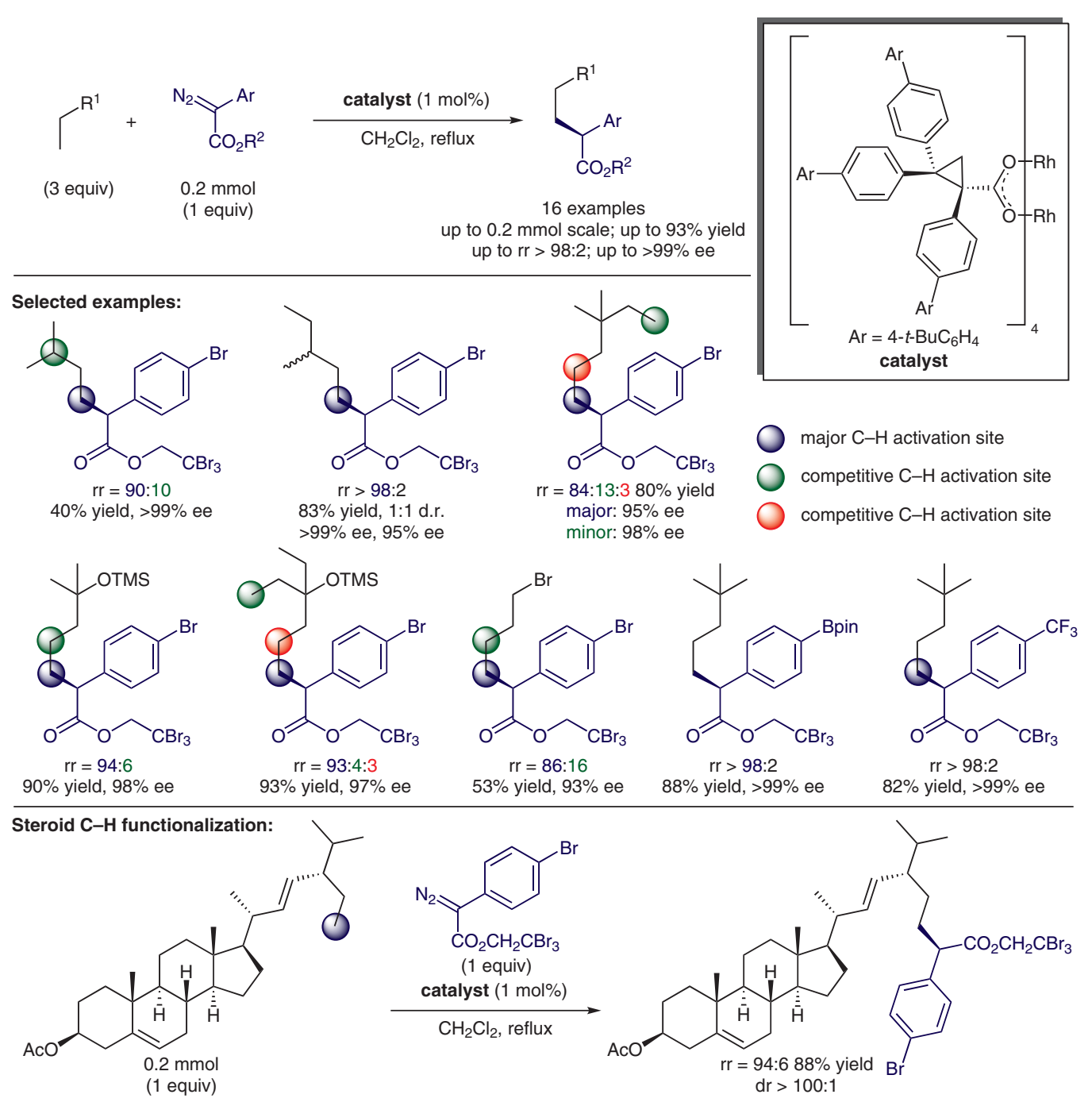

Significance: The authors previously described Rh-catalyzed functionalizations of secondary or tertiary C-H bonds (Liao et al. Nature 2016, 533, 230; Liao et al. Nature 2017, 551, 609). By tuning the catalyst, non-activated primary $\mathrm{C}-\mathrm{H}$ bonds are functionalized with excellent site and enantioselectivities.

SYNFACTS Contributors: Mark Lautens, José F. Rodríguez

Synfacts 2018, 14(11), 1143 Published online: 18.10.2018 Dol: 10.1055/s-0037-1611078; Reg-No.: L13218SF

\section{Category}

Metal-Catalyzed Asymmetric

Synthesis and

Stereoselective

Reactions

\section{Key words}

rhodium catalysis

C-H activation

carbenes

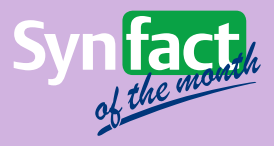

Comment: Subjecting chiral substrates to the reaction conditions allows access to either set of diastereomeric products when the appropriate catalyst enantiomer is employed. Stigmasteryl acetate could be selectively functionalized at its most sterically accessible primary $\mathrm{C}-\mathrm{H}$ bond. 